\title{
DESCRIPTIVE ANALYSIS OF GLYCEMIC AND LIPID PROFILES ASSOCIATED WITH MAJOR COMORBITIES IN PATIENTS WITH GOUT
}

Matheus Diniz Araújo Teixeira (UFAM, Manaus, AM, Brasil), Raissa Pires Medeiros (UFAM, Manaus, AM, Brasil), Rosana Barros Souza (UFAM, Manaus, AM, Brasil), Sandra Lúcia Euzébio Ribeiro (UFAM, Manaus, AM, Brasil)

\section{BACKGROUND}

Gout is an inflammatory osteoarticular disease characterized by the formation and accumulation of crystals of monosodium urate in the synovial fluid of joints and other tissues, causing damage. The potential severity of this health condition is enhanced by the association with several comorbidities, mainly type II diabetes mellitus (type II DM), dyslipidemia (DLP) and systemic arterial hypertension (SAH). The aim of this study was to perform a descriptive analysis of the glycemic and lipid profiles associated with the clinical history of gout patients treated at a Rheumatology Service.

\section{MATERIALS AND METHODS}

A descriptive cross-sectional study, carried out between 2017 and 2018, with patients diagnosed with gout were classified according to the criteria established by 2015 ACR/EULAR. The clinical, laboratorial and demograhic informations were collected and reviewed in the records of Service.

\section{RESULTS}

A total of 46 men with mean age of $63.78 \pm 9.03$ years and mean BMI of $28.27 \pm 3.54 \mathrm{~kg} / \mathrm{m}^{2}$ were studied. The disease duration had an average of $17.62 \pm 10.61$ years. In relation to the ethnic distribution, the population characterized was mostly composed by "pardos" (67,39\%). Participants had a considerable family history to: SAH (69.56\%), type 2 DM (45.65\%), gout (28.26\%) and DLP (21.74\%). The frequency of this comorbidities of the sample was: SAH (84,78\%), DLP (71,74\%), metabolic syndrome $(41,30 \%)$ and type $2 \mathrm{DM}(39,13 \%)$. In the evaluation of the lipid and glycemic profiles, the mean values were: total cholesterol was $189 \pm 45.34 \mathrm{mg} / \mathrm{dL}$, HDL equal to $41.23 \pm 10.16 \mathrm{mg} / \mathrm{dL}$; LDL was $114.21 \pm 36.96 \mathrm{mg} / \mathrm{dL}$, triglycerides was $197.54 \pm 111.91 \mathrm{mg} / \mathrm{dL}$, mean blood glucose was $109.98 \pm 37.08 \mathrm{mg} / \mathrm{dl}$ and the glycated hemoglobin was $6.18 \pm 1.24$. Individuals with type II DM (I) and DLP (II), compared to outhers without these comorbidities (III), had higher levels of glycated hemoglobin (I: 6.66 \pm 1.40 ; II: $6.06 \pm 1.33$; III: $5.70 \pm 0.93$ ), blood glucose (I:

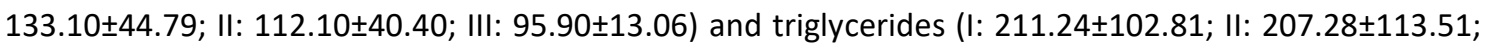
III: $150.7 \pm 88.92$ ), even though all were under pharmaceutical treatment. Correlation about gout attacks frequency after diagnosis between patients with type II DM vs without type II DM was significant $(9.25 \pm 5.21$ vs $7.21 \pm 5.14, p=0.0328)$, showed that the first group presented a greater number of attacks.

\section{CONCLUSION}

It was verified in this study that SAH, type II DM and DLP have high prevalence in gout individuals (and yours families), which may influence the clinical worsening of the disease and increase cardiovascular morbimortality. Therefore, it should have a better control of these factors present in patients with gout. 